\title{
Discovery and characterization of two new stem rust resistance genes in Aegilops sharonensis
}

\author{
Guotai Yu ${ }^{1,5} \cdot$ Nicolas Champouret $^{2,6} \cdot$ Burkhard Steuernagel $^{1} \cdot$ Pablo D. Olivera $^{3} \cdot$ Jamie Simmons $^{3} \cdot$ \\ Cole Williams $^{3} \cdot$ Ryan Johnson $^{3} \cdot$ Matthew J. Moscou $^{2} \cdot$ Inmaculada Hernández-Pinzón $^{2} \cdot$ Phon Green $^{2}$ • \\ Hanan Sela $^{4} \cdot$ Eitan Millet $^{4} \cdot$ Jonathan D. G. Jones $^{2} \cdot$ Eric R. Ward $^{2,5,7} \cdot$ Brian J. Steffenson $^{3} \cdot$ Brande B. H. Wulff $^{1,2}$
}

Received: 5 October 2016 / Accepted: 17 February 2017 / Published online: 8 March 2017

(c) The Author(s) 2017. This article is published with open access at Springerlink.com

\begin{abstract}
Key message We identified two novel wheat stem rust resistance genes, $S r-1644-1 S h$ and $S r-1644-5 S h$ in Aegilops sharonensis that are effective against widely virulent African races of the wheat stem rust pathogen.

Abstract Stem rust is one of the most important diseases of wheat in the world. When single stem rust resistance $(\mathrm{Sr})$ genes are deployed in wheat, they are often rapidly overcome by the pathogen. To this end, we initiated a search for novel sources of resistance in diverse wheat relatives and identified the wild goatgrass species Aegilops sharonesis (Sharon goatgrass) as a rich reservoir of resistance to wheat
\end{abstract}

Communicated by Hermann Buerstmayr.

Electronic supplementary material The online version of this article (doi:10.1007/s00122-017-2882-8) contains supplementary material, which is available to authorized users.

Brande B. H. Wulff

Brande.wulff@jic.ac.uk

1 John Innes Centre, Norwich Research Park, Norwich NR4 7UH, UK

2 The Sainsbury Laboratory, Norwich Research Park, Norwich NR4 7UH, UK

3 Department of Plant Pathology, University of Minnesota, Saint Paul, MN 55108, USA

4 Institute for Cereal Crops Improvement, Tel Aviv University, Tel Aviv 69978, Israel

5 2Blades Foundation, 1630 Chicago Avenue, Suite 1901, Evanston, IL 60201, USA

6 Present Address: J.R. Simplot Company, 5369 West Irving Street, Boise, ID 83706, USA

7 Present Address: AgBiome Inc, 104 T. W. Alexander Drive, Building 1, Research Triangle Park, NC 27709, USA stem rust. The objectives of this study were to discover and map novel $\mathrm{Sr}$ genes in Ae. sharonensis and to explore the possibility of identifying new $S r$ genes by genome-wide association study (GWAS). We developed two biparental populations between resistant and susceptible accessions of Ae. sharonensis and performed QTL and linkage analysis. In an $\mathrm{F}_{6}$ recombinant inbred line and an $\mathrm{F}_{2}$ population, two genes were identified that mapped to the short arm of chromosome $1 \mathrm{~S}^{\text {sh }}$, designated as $\mathrm{Sr}-1644-1 \mathrm{Sh}$, and the long arm of chromosome $5 S^{\text {sh }}$, designated as $\mathrm{Sr}-1644-5 \mathrm{Sh}$. The gene $\mathrm{Sr}$-1644-1Sh confers a high level of resistance to race TTKSK (a member of the Ug99 race group), while the gene $S r-1644-5 S h$ conditions strong resistance to TRTTF, another widely virulent race found in Yemen. Additionally, GWAS was conducted on 125 diverse Ae. sharonensis accessions for stem rust resistance. The gene $S r-1644-1 S h$ was detected by GWAS, while $S r-1644-5 S h$ was not detected, indicating that the effectiveness of GWAS might be affected by marker density, population structure, low allele frequency and other factors.

\section{Introduction}

Stem rust, caused by Puccinia graminis f. sp. tritici (Pgt), has historically been one of the most devastating wheat diseases in many production growing regions in the world. Since the 1950s, stem rust has been effectively controlled mainly through the deployment of cultivars carrying multiple stem rust resistance $(\mathrm{Sr})$ genes and elimination of the alternate host, the common barberry bush (Berberis vulgaris L.), in North America and Western Europe. However, emergence of the Pgt race TTKSK (a member of the Ug99 race group) in east Africa in the 1998-1999 growing season and its spread to other areas has posed a serious threat 
to world wheat production because of its virulence for several widely used $\mathrm{Sr}$ genes (Singh et al. 2011). To date, 11 races in the Ug99 race group have been identified and characterised by their diverse virulence spectra on defined $\mathrm{Sr}$ genes (Newcomb et al. 2016; Singh et al. 2015). Many of these $\mathrm{Sr}$ genes have been overcome by one or more of these races, including $S r 24$ (Jin et al. 2008), Sr31 (Pretorius et al. 2000), Sr36 (Jin et al. 2009) and SrTmp (Newcomb et al. 2016). Recently, a severe, localized stem rust epidemic developed on the variety Digalu in southern Ethiopia during November-December 2013. Digalu carries SrTmp and is resistant to race TTKSK; however, the epidemic was caused by race TKTTF, which is not part of the Ug99 race group (Olivera et al. 2015). Deployment of single $\mathrm{Sr}$ genes in wheat often leads to the rapid appearance of resistancebreaking strains of Pgt. However, the simultaneous deployment of multiple, broad spectrum $\mathrm{Sr}$ genes in a single cultivar might provide more long term resistance (Singh et al. 2006, 2011).

According to the online $S r$ gene catalogue for wheat, more than $50 \mathrm{Sr}$ genes have been identified to date, including tetraploid and hexaploid wheat, and its wild relatives (McIntosh et al. 2013). Most of the genes identified in domesticated wheat have not proven effective against newly emerged $P g t$ races (Singh et al. 2006, 2011). In some cases, this may be due to these $\mathrm{Sr}$ genes being present in common varieties (Roelfs and McVey 1979) that have been grown on a large scale for a long period of time (e.g. Sr6; Tsilo et al. 2009) in areas where stem rust is prevalent, thus exerting extreme pressure on the pathogen to overcome these genes. Wild wheat relatives are a particulary rich source of $\mathrm{Sr}$ genes, e.g. $\mathrm{Sr} 24, \mathrm{Sr} 25$, Sr26, Sr32, Sr33, Sr36, Sr37, Sr38, Sr39, Sr40, Sr43, Sr44, Sr45, Sr47, Sr50, Sr51, Sr52, and Sr53 which have all been introgressed into hexaploid bread wheat (Bariana and McIntosh 1993; Dundas et al. 2007; Anugrahwati et al. 2008; Liu et al. 2011a, b, 2013; Niu et al. 2011, 2014; Qi et al. 2011; Klindworth et al. 2012; Mago et al. 2013; Periyannan et al. 2013; McIntosh et al. 2013). Many of these genes have already been deployed in cultivated wheat or have entered into breeding programmes and thus may come under a higher risk of being overcome. It is necessary therefore to continue identifying new $\mathrm{Sr}$ genes and ideally deploy these as multi-Sr gene combinations to promote their longevity in the field.

Aegilops sharonensis Eig, or Sharon goatgrass $\left(\mathrm{S}^{\text {sh }}\right.$ genome), is a wild diploid relative of hexaploid wheat. Some preliminary work on this species (Olivera et al. 2007, 2010, 2013; Bouyioukos et al. 2013; Scott et al. 2014) has demonstrated its potential as a source of new resistance genes to important fungal pathogens (Olivera et al. 2007; Scott et al. 2014). Olivera et al. (2007) reported that the frequency of resistance in Ae. sharonensis accessions was highest to wheat powdery mildew
(79-83\%) and wheat leaf rust (60-77\%). Resistance to stem rust was also common, although the percentage of resistant accessions varied markedly depending on the pathogen race-13\% to race TTTTF, $69 \%$ to TTKSK, and $72 \%$ to race QCCJB. The frequency of resistance was intermediate to stripe rust (45\%) and low to tan spot (15-29\%) and spot blotch (0-34\%). Interspecies hybridization between wheat and Ae. sharonensis is restricted due to the presence of gametocidal genes in Ae. sharonensis (Millet et al. 2014; Knight et al. 2015). Therefore, the introgression of Ae. sharonensis genes into wheat has been limited (Millet et al. 2014). For this reason, this species remains a largely untapped reservoir of disease resistance genes. The objectives of this study were to identify novel $\mathrm{Sr}$ genes in $\mathrm{Ae}$. sharonensis and to exploit the possibility of finding $S r$ genes by genome-wide association study (GWAS).

\section{Materials and methods}

\section{Plant materials}

We developed two biparental populations of Ae. sharonensis: a recombinant inbred line $\left(\mathrm{RIL}_{5: 6}\right)$ and an $\mathrm{F}_{2}$ population. The RIL population was developed from a cross between the accessions AEG-2189 (AEG is the first three letters of the word "Aegilops") and AEG-1644 (Supplementary Table 1), while the $\mathrm{F}_{2}$ population was developed from a cross between AEG-2189 and AEG-409 (accessions 2189, 1644 and 409 hereafter). Accessions 1644 and 409 are stem rust resistant parents, while 2189 is a susceptible parent. For both the $2189 \times 1644$ RIL and the $2189 \times 409 \mathrm{~F}_{2}$ populations, we phenotyped and genotyped 92 lines/individuals along with the respective parents and two $F_{1}$ plants. The $92 F_{6}$ lines and $92 F_{2}$ individuals were randomly selected. For GWAS, we evaluated a diversity panel comprising 125 accessions spanning the geographical range of the species (Supplementary Table 2). Each accession was increased at least twice under controlled glasshouse conditions whereby individual spikes were bagged to prevent out-crossing to reduce heterozygosity prior to genotyping and phenotyping. Spikes of all accessions were bagged to prevent possible out-crossing. Accessions can be obtained from John Innes Centre Germplasm Resources Unit (http://www.jic.ac.uk/germplasm/) and the Harold and Adele Lieberman Germplasm Bank Tel-Aviv University (http://www.genesys-pgr.org/ wiews/ISR003). Wheat accessions Chinese Spring and McNair 701 were used as susceptible controls in the rust phenotyping experiments. 


\section{Pathogen races}

Three races of $P g t$ with diverse virulences and geographic origins were used in this study to detect resistance genes in Ae. sharonensis. Race TPMKC was the predominant race in the United States during the 1990s, and it is virulent on Sr36 (McVey et al. 2002). Race TRTTF has been identified in Yemen and Ethiopia, and it is virulent to four $S r$ genes that are effective to race TTKSK (Sr13, Sr36, SrTmp, and $S r 1 R S^{\text {Amigo }}$ ) (Olivera et al. 2012). TTKSK was the first race identified in the Ug99 race group and is virulent for $\operatorname{Sr} 31$, one of the most widely used stem rust resistance genes in wheat (Pretorius et al. 2000).

\section{Stem rust resistance evaluation}

Stem rust phenotyping was conducted in the Biosafety Level-3 Containment Facility on the St. Paul campus of the University of Minnesota. Evaluations were done at the seedling stage, when the second leaves of plants were fully expanded, about 10-12 days after sowing (Williams et al. 1992). The RIL population was tested against races TPMKC, TRTTF, and TTKSK in two replicate experiments with an additional test on selected lines. The $2189 \times 409 \mathrm{~F}_{2}$ population was tested with race TTKSK. The 125 accessions in the diversity panel were evaluated against races TPMKC, TRTTF, and TTKSK in two replicate experiments with an additional test on selected lines. Protocols for rust inoculations and conditions for subsequent incubation of plants were as described by Scott et al. (2014).

Seeds were sown in super-cell cones (Stuewe and Sons, Inc., Corvallis, OR) or pots filled with 1:1 mixture of steam-sterilized native soil and Sunshine MVP growing mix (Sun Gro Horticulture Distribution Inc., Bellevue, WA) (Scotts-Sierra Horticultural Products Company, Marysville, $\mathrm{OH})$. Five seeds per replicate per line were sown in the pot for $2189 \times 1644$ RIL population and the association panel, while $2189 \times 409 \mathrm{~F}_{2}$ individuals were sown in cones. Water soluble 15-0-15 fertilizer (JR Peters Dark Weather) was applied when the plants emerged and then 20-10-20 fertilizer was applied (JR Peters 20-10-20 Peat-Lite) 1 and 7 days after inoculation. The seedlings were grown in the greenhouse at $20-23{ }^{\circ} \mathrm{C}$ with $16 / 8 \mathrm{~h}$ (day/night) photoperiod. At the second leaf stage, 10-12 days after sowing, when the second leaf was fully expanded, the seedlings were inoculated with Pgt urediniospores (Williams et al. 1992).

Infection types were recorded for each plant at 12-14 days post-inoculation, using the infection type (IT) scale described by Stakman et al. (1962), where $0=$ immune, necrotic flecks, $1=$ minute uredinia surrounded by distinct necrosis, $2=$ small to medium sized uredinia surrounded by chlorosis or necrosis, $3=$ medium sized uredinia sometimes surrounded by chlorosis, and $4=$ large uredinia without chlorosis. The additional notations of "-" or "+" for ITs 1, 2, or 3 were applied when the uredinia were slightly smaller or larger than those classically described. For the purpose of mapping, only the predominant (first listed) IT was used. ITs $0,1-, 1,1+, 2-$, $2,2+, 3-, 3,3+$, and 4 were converted into the respective numeric values $0,0.33,0.67,1,1.33,1.67,2,2.33,2.67$, $3,3.33$, and 4 to make the scores amenable to quantitative genetics. On average, 4.0 plants for $2189 \times 1644$ RIL and 4.1 plants for the association panel were scored, while the $2189 \times 409 \mathrm{~F}_{2}$ plants were scored as individuals.

\section{Oligo pool assay (OPA) genotyping}

We used the whole genome shotgun (WGS) assembly of Ae. sharonensis accession 1644 (Mayer et al. 2014) as a reference for SNP calling. We also selected accession 2189 for WGS assembly because of its susceptibility to race TTKSK and its use as a parent in the two mapping populaions. WGS reads from the Ae. sharonensis accession 2189 (PRJEB5333) were mapped to the 1644 reference using Burrows-Wheeler Aligner ( $\mathrm{Li}$ and Durbin 2009) and SNPs were called using samtools mpileup ( $\mathrm{Li}$ et al. 2009). SNPs were filtered based on unambiguous read support. We also mapped reads from the leaf transcriptomes of 16 accessions (Supplementary Table 3) (PRJEB5340) to the reference using TopHat (Kim et al. 2013) and called SNPs between either of the three accessions 409, 2020 and 2172 versus accession 2189. SNPs were filtered based on unambiguous read support. To comply with OPA genotyping requirements, all positions with SNPs from either genomic or transcriptomic analysis were then filtered for having no additional variation called within $80 \mathrm{bp}$ in both directions and containing contiguous flanking sequence of $\geq 100 \mathrm{bp}$ in both directions. Contigs of the reference assembly were anchored to the barley (Hordeum vulgare L.) genome (Mayer et al. 2014) by synteny. This was done by best reciprocal BLAST hit to barley proteins. For each cM position in the barley genome, we selected up to three of our SNPs that were located on anchored contigs. Additionally, we selected randomly chosen SNPs from our list. In this way, 3072 SNPs were selected and sent to the University of California, Los Angeles, Neuroscience Genomics Core (UNGC) for usability scoring. According to this score, we selected a final set of 1536 SNPs as probes for our OPA assay (Supplementary Table 4). All SNPs selected had an Illumina final score of 0.604 or higher.

For the $2189 \times 409 \mathrm{~F}_{2}$ population, we extracted DNA from each $\mathrm{F}_{2}$ plant. For the $2189 \times 1644$ RIL population and diversity panel, each line was planted in a single pot. Leaves were taken from a single young plant and DNA was extracted following the protocol described by $\mathrm{Yu}$ et al. 
(2010). OPA genotyping was done at the UNGC and the genotypes were manually curated.

\section{DNA and RNA extraction for sequencing}

Genomic DNA was isolated from purified nuclei (Brenchley et al. 2012) and sequenced by The Genome Analysis Centre (TGAC; http://www.tgac.ac.uk, UK) and Eurofins (http://www.eurofins.eu, Ebersberg, Germany) on an Illumina HiSeq2000. Accession 1644 was sequenced from three paired-end (PE) libraries with an insert size of 300 bp (International Wheat Genome Sequencing Consortium 2014). Accession 2189 was sequenced from one overlapping 200 bp PE library, two 300 bp PE libraries, one 700 bp PE library, and two mate-pair-like libraries using a proprietary protocol (Eurofins, Ebersberg, Germany) with 3000 and 8000 bp insert sizes. Raw data have been made available through the European Nucleotide Archive (ENA), Study IDs PRJEB4849 and PRJEB5333.

Total RNA was extracted from tissue obtained from second and third leaves of 16 Ae. sharonensis accessions using the TRI Reagent (Sigma-Alrich) according to the manufacturer's instructions (Supplementary Table 3). RNA samples were depleted of DNA by treatment with DNase and further purified using the RNeasy MinElute kit (Qiagen Ltd.). RNA yield and quality were assessed using a Nanodrop spectrophotometer (Thermo Scientific) and a Bioanalyzer 2100 Nanochip (Agilent Technologies). RNA was sequenced as paired-ends at TGAC by multiplexing four samples per lane on an Illumina HiSeq 2000 and using the Illumina TruSeq RNA kit. Raw data have been made available through ENA, Study ID PRJEB5340.

\section{ANOVA, linkage map construction, and QTL mapping}

The program PAST (Belkhir et al. 1996-2004; http:// univ-montp2.fr/ genetix) was used for ANOVA. The Map Manager QTX2b program (Manly et al. 2001), with $p$ value set to 0.001 , was used to make the genetic linkage maps for each population using the Kosambi function (Kosambi 1944). Markers were selected to include those with the least missing data points $(<4)$, and minimum data points for a minor allele ( $>28$ for the RIL population and $>8$ for the $\mathrm{F}_{2}$ population). To take into account the different recombination rates between the $\mathrm{F}_{2}$ and $\mathrm{F}_{6}$ populations and the different markers successfully mapped in them, a consensus map was manually constructed based on common markers on the individual linkage maps. The common markers' genetic positions were averaged and the non-common markers' genetic positions were determined relative to the mean interval. In addition to QTX, Carthagene was also employed to generate genetic linkage maps using the Kosambi function (Kosambi 1944). We used command "Build" at LOD 3 to make individual genetic linkage maps for the $2189 \times 1644$ RIL and $2189 \times 409 \mathrm{~F}_{2}$ populations (Supplementary Table 5) and used command "Mergor" and then "Build" to construct the consensus map (Supplementary Table 6). The consensus maps constructed manually and with Carthagene were found to be highly correlated (Supplementary Fig. 1). However, more than 200 markers on the individual linkage maps for the $2189 \times 1644 \mathrm{RIL}$ and $2189 \times 409 \mathrm{~F}_{2}$ populations were left out of the Carthagene consensus map. Therefore, we decided to proceed with the manually constructed consensus map for all subsequent analysis. QTL mapping for biparental populations was conducted using QTL Cartographer (Wang et al. 2006) using the default parameters except a $1 \mathrm{cM}$ step was applied.

For the diversity panel, the heterozygous genotypes were considered as missing. Data were filtered according to the following criteria. First, lines with $10 \%$ or more missing data points for all markers were removed. Second, a SNP that had a minor allele frequency of less than $5 \%$ was removed. Third, a SNP with missing data points in more than $10 \%$ of the lines was removed. Finally, three lines that had a cluster distance (Euclidean-single linkage) of less than 1.5 were removed.

\section{Linkage disequilibrium}

The program Tassel 4.04 (http://www.maizegenetics. net) was used to estimate the linkage disequilibrium (LD) parameter $r^{2}$ among loci. LD was first computed for all unlinked loci ( $>50 \mathrm{cM}$ and inter-chromosomal) of the whole genome and the pair-wise significance was computed. The parametric 95th percentile was taken as a threshold of $r^{2}$. Chromosome-wide $r^{2}$ was then separately computed for each chromosome on different loci. Then all $r^{2}$ were pooled from the seven chromosomes. The $r^{2}$ was plotted against genetic distance on the whole genome. The LOESS procedure of $r$ of PAST (Belkhir et al. 1996-2004; http://univ-montp2.fr/ genetix) was used to draw a smooth line of second-degree LOESS with a smooth factor of 0.5 (Cleveland 1979). The intersection of the LOESS curve and the threshold line was considered as the estimate of the extent of LD in the genome.

\section{Population structure, principal component, and kinship analysis}

Forty markers that had a genetic distance of $\sim 10 \mathrm{cM}$ were selected for population structure analysis. The program Structure 2.3.3 (Pritchard et al. 2000) was used to determine the number of subpopulations with the default admixture model and correlated allele frequencies (Falush et al. 2003). The program was run for each value of the subpopulation number ( $K=1$ to $K=6$ ), with burn-in phase of $10^{5}$ 
iterations and a sampling phase of $10^{5}$ replicates. Because the optimal $K$ was not able to be determined based on Ln $p(X \mid K)$, the first and second derivatives of $\operatorname{Ln} p(X \mid K)$ were also computed and $\Delta K$ was used to determine the optimal $K$. Accessions were discretely assigned to the subpopulation for which the probability was the largest among the subpopulations. The program PAST (Belkhir et al. 1996-2004; http://univ-montp2.fr/ genetix) was used to conduct the principal component analysis (PCA). For kinship analysis, SPAGeDi 1.3a (Hardy and Vekemans 2002) was used to compute the relative kinship matrix using 388 markers.

\section{Marker-stem rust resistance association analysis}

Tassel 4.04 was also used for marker-resistance association analysis. Associations between markers and transformed stem rust resistance scores were tested using a general linear model (GLM) and also a compressed mixed-effects linear model (MLM) where the marker being tested was considered as a fixed-effect factor, population structure factors as covariates, and kinship as a random-effect factor (Yu et al. 2006). Significance of associations between markers and stem rust resistance was based on 1000 permutations (Churchill and Doerge 1994) with GLM and MLM. Tassel does not allow experiment-wise permutations; therefore, permutation tests were performed by shuffling the phenotypic data 1000 times using a custom Python script, running the shuffled data in Tassel, and sorting $p$ values of each test in an Excel spreadsheet to get the smallest $p$ value of each test. The $-\log _{10} p$ at the 95th percentile of the 1000 permutations was taken as the threshold.

Removal of closely related accessions to generate a trained population was based on cluster analysis with 40 markers using program PAST (Belkhir et al. 1996-2004; http://univ-montp2.fr/ genetix). We removed 23 accessions with less than 0.4 of the relative distance (branch distance of an accession/the longest distance, Euclidean-single linkage). Each of the 23 accessions was randomly selected from a pair of the closest ones in the cluster.

\section{Results}

\section{Phenotyping and ANOVA}

The ITs for the parental accessions 1644, 409 and 2189 are shown in Fig. 1. Accessions 1644 and 409, showed high levels of resistance (ranging between 0 ; and 1;) to all three races of TPMKC (USA), TRTTF (Yemen), and TTKSK (Ug99; Kenya). In contrast, accession 2189 was susceptible to all three races (Fig. 1).

In the biparental populations made between the resistant and susceptible accessions, segregation for resistance was observed with all three races (Fig. 2). Plants showing IT $0 ; 1$, or 2 were considered resistant, while the ones showing 3 or 4 were considered susceptible. In the $2189 \times 1644$ RIL population, the ratio of the number of resistant to susceptible lines was very different from 1:1. For example, to race TTKSK, the number of resistant lines $(n=76)$ vastly exceeded the number of susceptible lines $(n=8)$ or segregating lines $(n=8)$ (i.e. showing both resistant and susceptible plants within the same line; Supplementary Table 1). In the $2189 \times 409 \mathrm{~F}_{2}$ population, the ratio of the number of resistant to susceptible plants was close to $3: 1 \quad(p=0.25)$ indicative of a single dominant resistance gene in 409 effective against TTKSK.
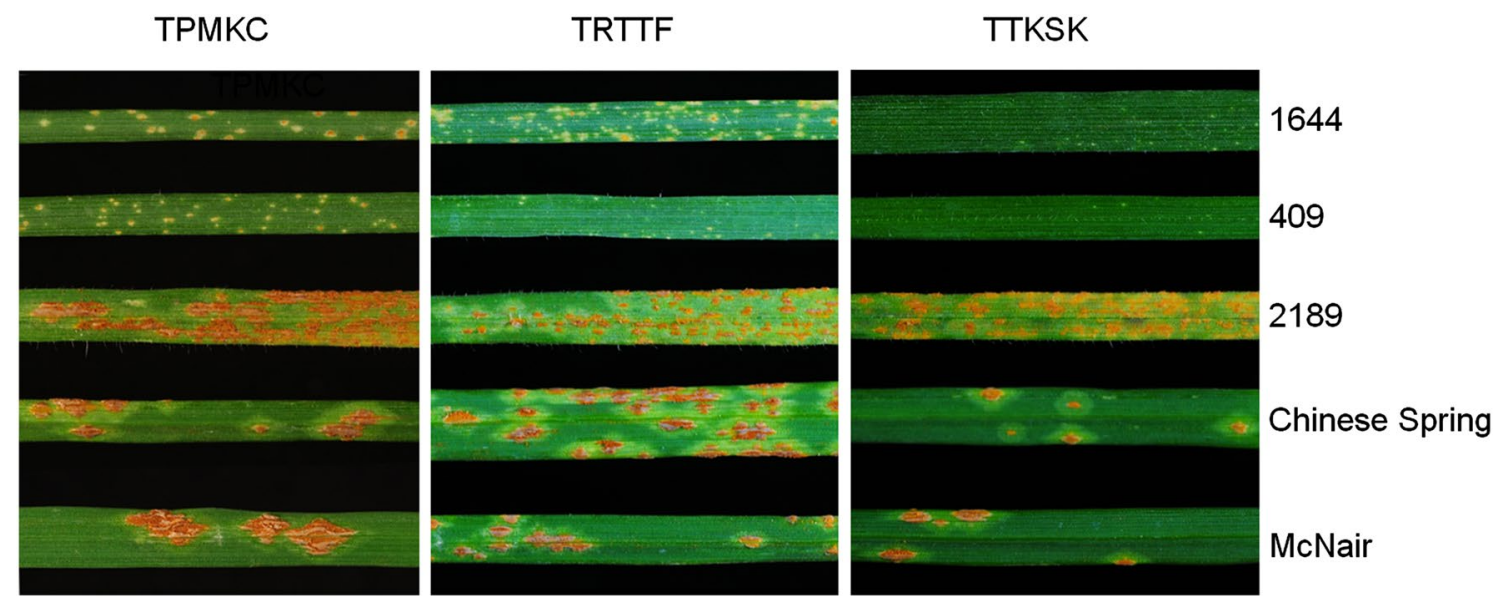

Fig. 1 Evaluation of Ae. sharonensis parental accessions and wheat controls for stem rust resistance at the seedling stage. Three Ae. sharonensis parental accessions $(1644,409,2189)$ and two wheat controls
(Chinese Spring and McNair) were tested against $P g t$ races TPMKC, TRTTF, and TTKSK 

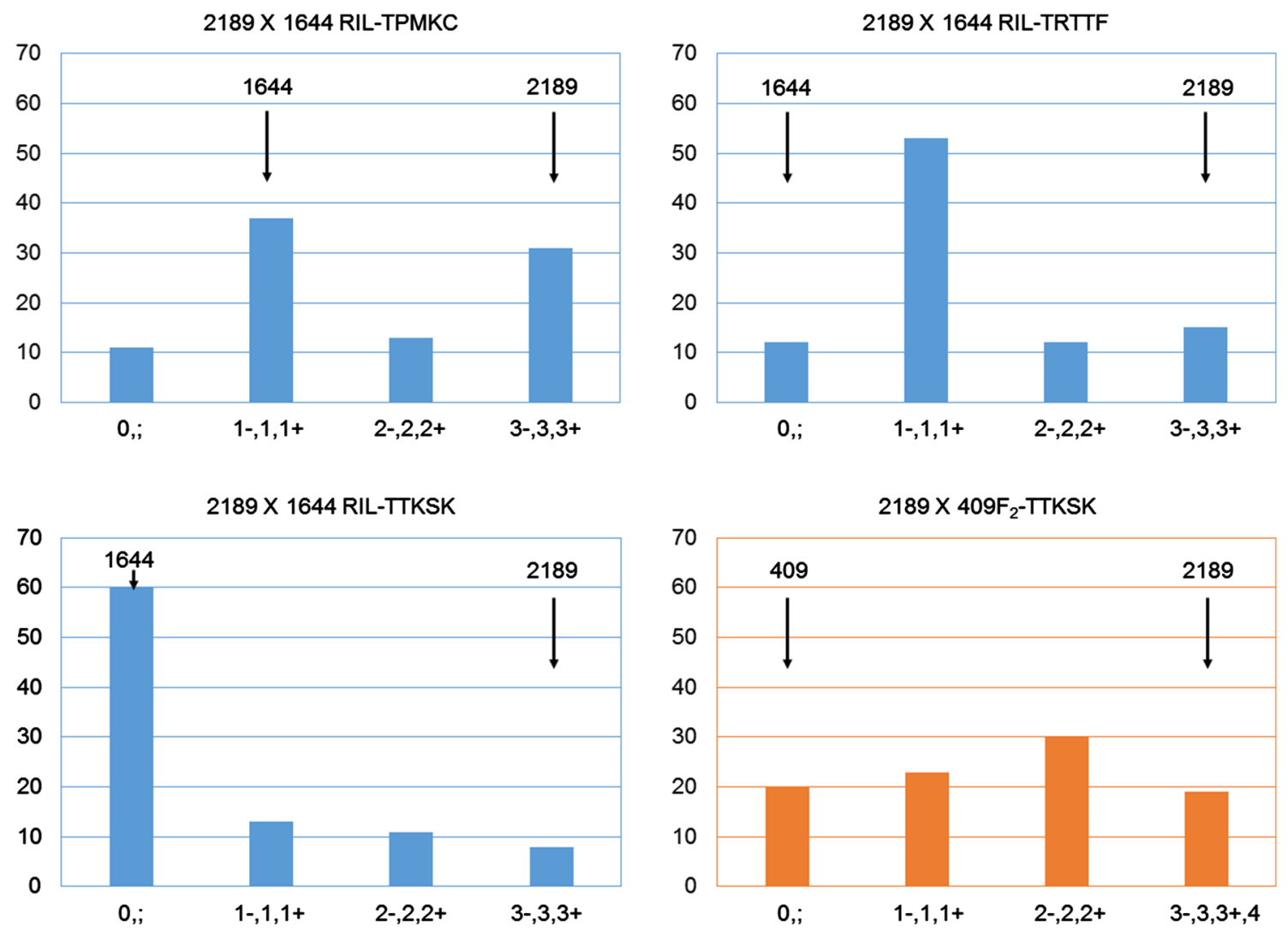

Fig. 2 Wheat stem rust infection type distributions in biparental populations of Ae. sharonensis. The $X$-axis indicates the infection type while the $Y$-axis indicates the number of individual lines/plant. Ninety-two $2189 \times 1644$ RILs (blue) were scored for their reactions

ANOVA was performed for the $2189 \times 1644$ RIL population and the association panel on two replicates (for QTL and association mapping, all scored plants were included). Differences among the RILs were highly significant based on the $F$ test (Supplimentary Table 7). For the association mapping panel comprised of 125 accessions, highly significant differences were found for the IT scores to all three races (Supplementary Table 8).

\section{Genetic linkage map}

The genetic linkage map for the $2189 \times 1644$ RIL population was created based on a RIL population model, while the genetic linkage map for the $2189 \times 409 \mathrm{~F}_{2}$ population was based on an $F_{2}$ population model. Since the RIL and $\mathrm{F}_{2}$ are different types of populations, a consensus linkage map was manually constructed based on the two individual maps. Based on the collinearity between Ae. sharonensis and barley, we were able to assign the individual chromosome groups and to determine the orientation of each chromosome. We assigned chromosome names $1 S^{\mathrm{Sh}}$ to $7 \mathrm{~S}^{\mathrm{Sh}}$ corresponding to $1 \mathrm{H}-7 \mathrm{H}$ (Supplementary Fig. 2).

to $P g t$ races TPMKC, TRTTF and TTKSK, while $922189 \times 409 \mathrm{~F}_{2}$ plants (orange) were scored for their reaction to race TTKSK only. Parental phenotypes are indicated by vertical arrows. (Color figure online)

The consensus genetic linkage map is composed of 727 OPA markers. The total length of the seven chromosomes is $630.7 \mathrm{cM}$ with an average distance of $0.9 \mathrm{cM}$ between two neighbouring markers. The largest gap in the map is $18.2 \mathrm{cM}$ on chromosome $2 \mathrm{~S}^{\mathrm{Sh}}$. Two other big gaps $(>10 \mathrm{cM})$ are located on the long arm of chromosome $4 \mathrm{~S}^{\mathrm{Sh}}$ and the short arm of chromosome $5 \mathrm{~S}^{\mathrm{Sh}}$. While $4 \mathrm{~S}^{\mathrm{Sh}}$ is the shortest chromosome $(58.8 \mathrm{cM}), 5 \mathrm{~S}^{\mathrm{Sh}}$ is the longest one $(109.7 \mathrm{cM})$.

\section{Biparental population mapping}

QTL mapping was used to identify the genetic location of genes conferring stem rust resistance in the two biparental genetic populations. The QTL mapping was done using the genetic linkage maps generated for the $\mathrm{F}_{2}$ and RIL populations, respectively. We used 1000 permutations to determine the LOD threshold for the significance of a QTL. The significant QTLs are listed in Table 1. Two QTLs with large phenotypic effects were identified and mapped to chromosome $1 S^{\text {Sh }}$ and $5 S^{S h}$ in both mapping populations. Although the map positions for the two QTLs peak in the populations 
Table 1 Significant QTL for stem rust resistance in biparental populations $(2189 \times 1644$ recombinant inbred line and $2189 \times 409$ $\mathrm{F}_{2}$ populations) of Aegilops sharonensis to races TPMKC, TRTTF, and TTKSK identified by interval mapping

\begin{tabular}{llllrrrr}
\hline Population & Race & Chr & \multicolumn{1}{c}{ cM } & \multicolumn{1}{c}{ CMP } & LOD & $R^{2}(\%)$ & \multicolumn{1}{l}{$A$} \\
\hline $2189 \times 1644$ RIL & TPMKC & $1 S^{\text {Sh }}$ & 54.5 & 75,425 & 46.0 & 89 & -1.06 \\
& TRTTF & $1 S^{\text {Sh }}$ & 54.8 & 9117 & 4.2 & 19 & -0.37 \\
& TRTTF & $5 S^{\text {Sh }}$ & 49.6 & 71,988 & 10.3 & 40 & -0.54 \\
& TTKSK & $1 S^{\text {Sh }}$ & 52.8 & 121,474 & 13.7 & 51 & -0.68 \\
$2189 \times 409 \mathrm{~F}_{2}$ & TTKSK & $5 S^{\text {Sh }}$ & 41.6 & $1,447,498$ & 5.2 & 23 & -0.46 \\
\hline
\end{tabular}

Threshold: LOD 2.9, 2.8, and 2.9 for RIL at $p=0.05$ against TPMKC, TRTTF, and TTKSK, respectively and for $\mathrm{F}_{2}$ population threshold: LOD 3.4 at $p=0.05$ based on 1000 permutation

Chr chromosome, $C M P$ the closet marker, $R^{2}$ explained phenotypic variation in percentage, $A$ additive effect at slightly different positions, they were located in the same narrow region (Fig. 3). Thus, we tentatively named them Sr-QTL-1Sh and Sr-QTL-5Sh, respectively.

The two QTL behaved differently in the two populations against the three races (Fig. 3). In the $2189 \times 1644$ RIL population, the Sr-QTL-1Sh conferred a high level of resistance to race TTKSK (explaining $51 \%$ of the phenotypic variation) and an extremely high level of resistance to TPMKC (explaining $89 \%$ of the variation). However, it conferred a lower level of resistance to race TRTTF (explaining only $19 \%$ of the variation). In contrast, Sr-QTL5Sh conferred a high level of resistance to TRTTF (explaining $40 \%$ variation; Table 1 ). In the $2189 \times 409 \mathrm{~F}_{2}$ population, the Sr-QTL-1Sh conferred a high level of resistance to TTKSK (explaining $82 \%$ of the variation), but the Sr-QTL5Sh did not confer resistance to TTKSK (Table 1).

\section{Linkage disequilibrium}

Among the 727 OPA markers comprising the consensus genetic linkage map, 153 non-redundant markers (only one marker at a genetic linkage position) were selected for linkage disequilibrium analysis. The $r^{2}$ results and respective $p$ values are shown in Fig. 4. Based on whole genome unlinked (>50 cM or inter-chromosomal) markers, the significance threshold for LD was determined to be 0.09 . Since LOESS curves did not intercept the threshold line (Fig. 4), the extent of LD for the whole genome could not be determined.

\section{Population structure}

The posterior probability of the data did not peak in the range of 1-6 subpopulations. However, the $\Delta K$ of the $\mathrm{Ln}$ $p(X \mid N)$ on 30 replicates had the highest value at the three subpopulations (Fig. 5a, b). Therefore, three subpopulations were identified based on the $\Delta K$ method proposed by Evanno et al. (2005). The three subpopulations included
31,42 , and 52 lines, which had a mean $F_{\mathrm{ST}}$ equal to 0.34 , 0.30 , and 0.31 , respectively.

The principal component analysis (PCA) confirmed the identification of the three subpopulations by the program PAST. Figure 5c shows projections of the PCA clouds in the space defined by three orthogonal axes (the first three components). Three clouds were formed in the space although four accessions (AS_06480, AS_06485, AS_06489, and AS_06637) of subpopulation 3 fell into subpopulation 1 .

In general, the Ae. sharonensis accessions of subpopulation 2 were more resistant than the ones of subpopulation 1, and accessions of subpopulation 3 were less resistant than the ones of subpopulation 2 against races TPMKC, TRTTF, and TTKSK. Within subpopulation 1, only a few of the accessions showed resistance to TPMKC. Almost half of the accessions were resistant to TRTTF, and the majority of the accessions were resistant to TTKSK. Within subpopulation 2, only 1 out of the 42 accessions was susceptible to TRTTF or TTKSK, but 13 accessions were susceptible to TPMKC. Within subpopulation 3, while the vast majority of the 42 accessions were resistant to TRTTF or TTKSK, two-fifths of the accessions were susceptible to TPMKC (Supplementary Table 2).

Geographically, subpopulation 1 (characterized by susceptibility, in particular to race TTKSK) was found in an area north of Haifa (Akko Plain region) (Fig. 5d). In contrast, subpopulation 2 was collected south of, but close to Haifa (Coast of Carmel region), and all the accessions, but one, were resistant to TTKSK. Subpopulation 3 was collected mainly around Tel Aviv (Sharon Plain and Phillistean Plain regions), but included some accessions from the Haifa area. The majority of accessions from this subpopulation were resistant to TTKSK.

\section{Association mapping}

The results of marker-resistance association analysis are shown in Fig. 6. Based on GLM, seven markers, 7283 and 

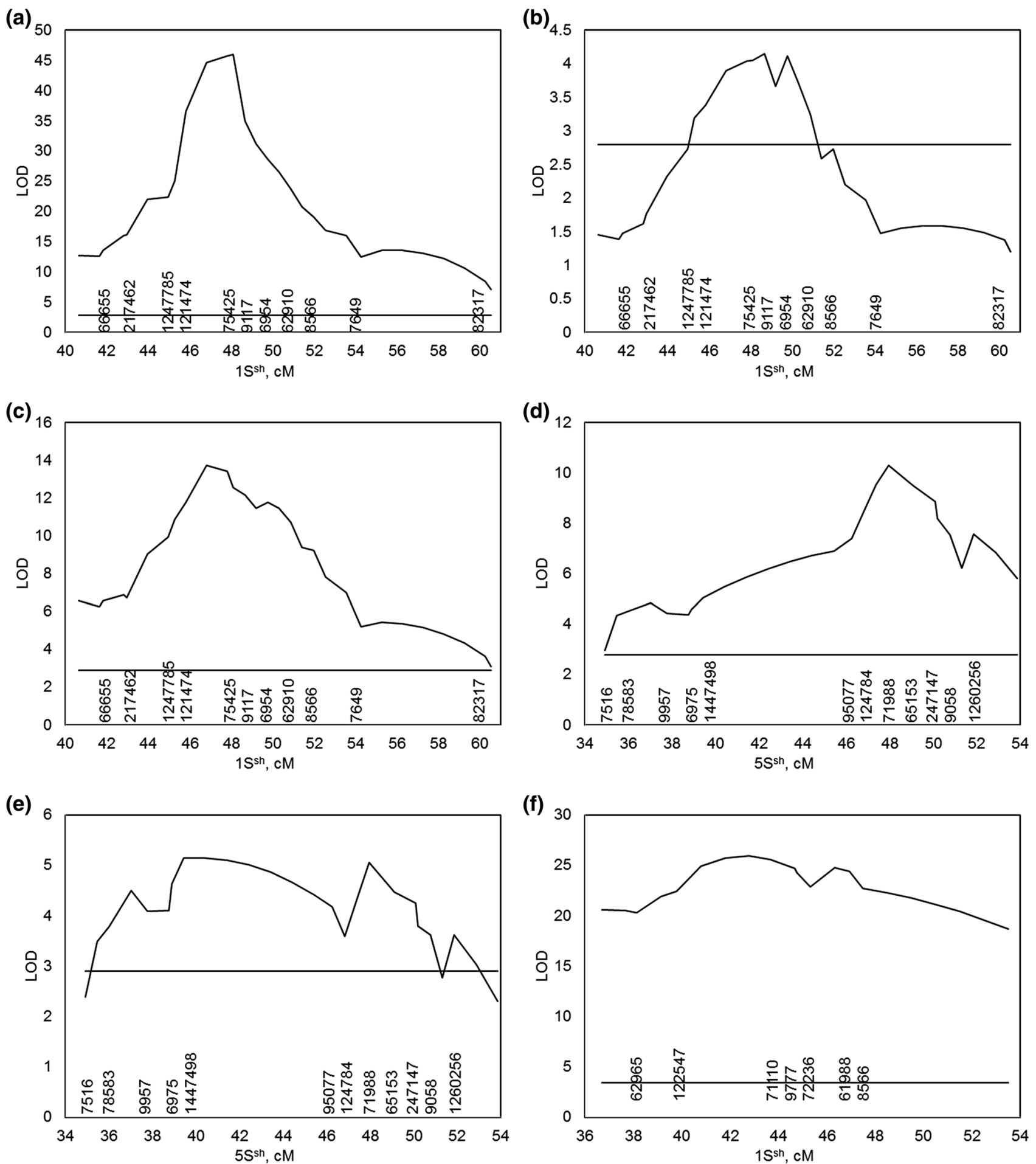

Fig. 3 QTL interval mapping in the $2189 \times 1644$ RIL and $2189 \times 409$ $\mathrm{F}_{2}$ populations were performed on the stem rust resistance to pathogen races TPMKC, TRTTF, and TTKSK. The horizontal lines indicate the thresholds based on 1000 permutations. a Scan on partial chromosome $1 S^{\text {sh }}$ for $2189 \times 1644$ RIL against TPMKC, b scan on partial chromosome $1 S^{\text {sh }}$ for $2189 \times 1644$ RIL against TRTTF, $\mathbf{c}$ scan

on partial chromosome $1 \mathrm{~S}^{\text {sh }}$ for $2189 \times 1644$ RIL against TTKSK, d scan on partial chromosome $5 S^{\text {sh }}$ for $2189 \times 1644$ RIL against TRTTF, e scan on partial chromosome $5 S^{\text {sh }}$ for $2189 \times 1644$ RIL against TTKSK, $f$ scan on partial chromosome $1 \mathrm{~S}^{\text {sh }}$ for $2189 \times 409 \mathrm{~F}_{2}$ against TTKSK 
(a)

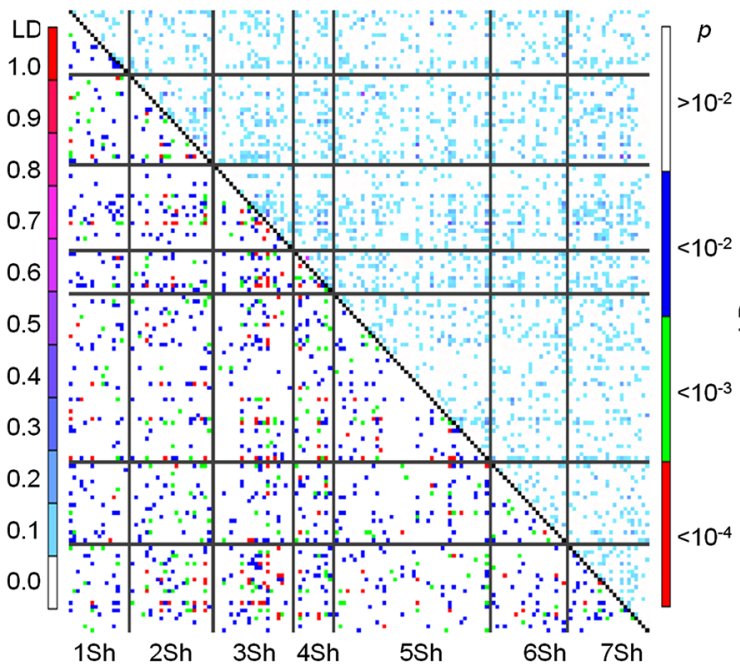

Fig. 4 LD $\left(r^{2}\right)$ and genome-wide average LD decay estimated from 125 Ae. sharonensis accessions. a The lower triangle represents the linkage disequilibrium (LD) while the upper triangle represents the $p$

6954 on $1 S^{\text {Sh }}, 91,247$ on $2 S^{\text {Sh }}, 70,039,61,971$, and 71,850 on $3 \mathrm{~S}^{\mathrm{Sh}}$, and 60,772 on $6 \mathrm{~S}^{\mathrm{Sh}}$ were significantly associated with resistance to TPMKC at the $-\log _{10} p=3.9$. These markers explained $12-16 \%$ of the phenotypic variation of the resistance to TPMKC. For resistance to TRTTF, eight markers, 7283 and 7215 on $1 \mathrm{~S}^{\mathrm{Sh}}, 62,411,103,660$ and 246,912 on $2 S^{\text {Sh }}, 71,850$ on $3 S^{\text {Sh }}, 62,473$ on $6 S^{\text {sh }}$ and $1,248,445$ on $7 \mathrm{~S}^{\mathrm{Sh}}$ were significantly associated with resistance. These markers explained $11-22 \%$ of the phenotypic variation. Against TTKSK, six markers, 7283 on $1 \mathrm{~S}^{\mathrm{Sh}}, 71,850,70,039,61,971$, and 70,177 on $3 \mathrm{~S}^{\mathrm{Sh}}$, and 7148 on $4 S^{\text {Sh }}$, were significantly associated with resistance. They explained $12-18 \%$ of the phenotypic variation of the resistance.

Based on a mixed linear model (MLM), three markers, 91,247 on $2 S^{S h}, 61,971$ on $3 S^{S h}$, and 60,772 on $6 S^{\text {Sh }}$ were significantly associated with resistance to TPMKC at the arbitrary threshold $-\log _{10} p=2$. These markers explained 7, 6, and $7 \%$ of the phenotypic variation for resistance to TPMKC, respectively. For resistance to TRTTF, two markers, namely 103,660 on $2 S^{\text {Sh }}$ and 63,580 on $3 S^{\text {Sh }}$ were found significantly associated with resistance, explaining 8 and $6 \%$ of the phenotypic variation, respectively. Three markers, 103,660 on $2 S^{\text {sh }}$, 61,971 on $3 S^{S h}$, and 7148 on $4 S^{\text {Sh }}$, were significantly associated with resistance to TTKSK. They explained 6,8 , and $8 \%$ of the phenotypic variation for resistance, respectively. However, none of these marker-resistance associations reached the threshold based on 1000 permutations (Fig. 6b). (b)

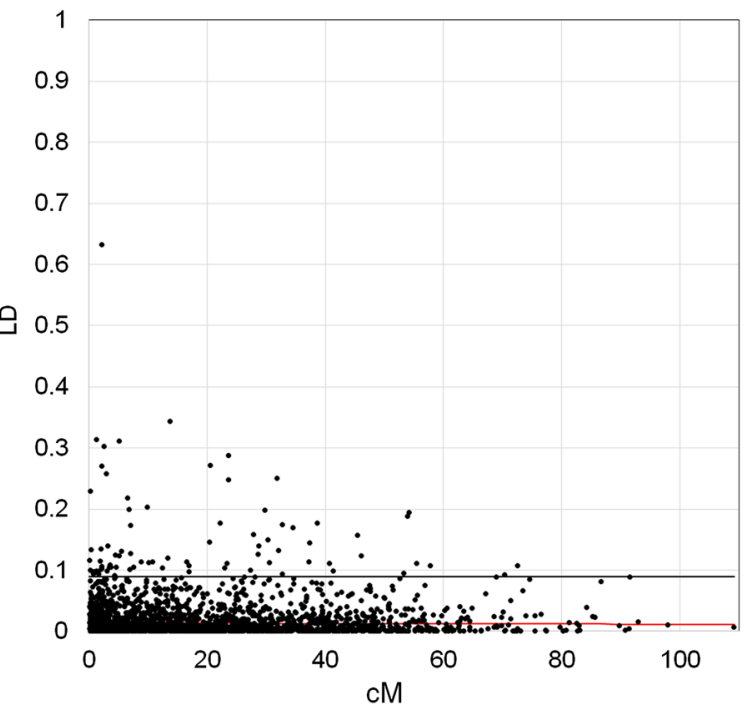

values for the $\mathrm{LD}$. In $\mathbf{b}$, the horizontal line indicates the threshold and the red line represents the LOESS curve. (Color figure online)

Due to possible over-correcting for population structure and kinship (Pasam et al. 2012; Zegeye et al. 2014), we developed a different GLM approach, which does not involve statistical correction for these factors. To this end, we trained the population by manually removing 23 accessions which we found to be closely related to another. With GLM on the trained population (GLM-TP; Fig. 6c), one marker, 62,024 on $1 \mathrm{~S}^{\mathrm{Sh}}$, was significantly associated with resistance to TPMKC at the $-\log _{10} p=4.0$. This marker explained $17 \%$ of the phenotypic variation for resistance to this race. For resistance to TRTTF, two markers, namely 7283 on $1 \mathrm{~S}^{\text {Sh }}$ and 9115 on $3 \mathrm{~S}^{\mathrm{Sh}}$ were found significantly associated with resistance. The two markers explained 17 and $14 \%$ of the phenotypic variation, respectively. Against TTKSK, no marker was found significantly associated with resistance. The markers found on chromosome $1 \mathrm{~S}^{\mathrm{Sh}}$ are close to Sr-QTL-1Sh: marker 62,024 mapped to the same position $\left(54.5 \mathrm{cM}, 1 \mathrm{~S}^{\mathrm{Sh}}\right)$ as marker 75,425 , which is the marker closest to the QTL peak against TPMKC, while marker 7283 mapped to the same position $\left(54.8 \mathrm{cM}, 1 \mathrm{~S}^{\mathrm{Sh}}\right)$ as marker 9117 , which is the marker closest to the QTL peak against TRTTF in the $2189 \times 1644$ RIL population (Fig. 3; Table 1).

\section{Discussion}

\section{Consensus genetic linkage map}

Aegilops sharonensis is a wild diploid wheat relative native to Israel and southern Lebanon. The limited genetic and 
(a)

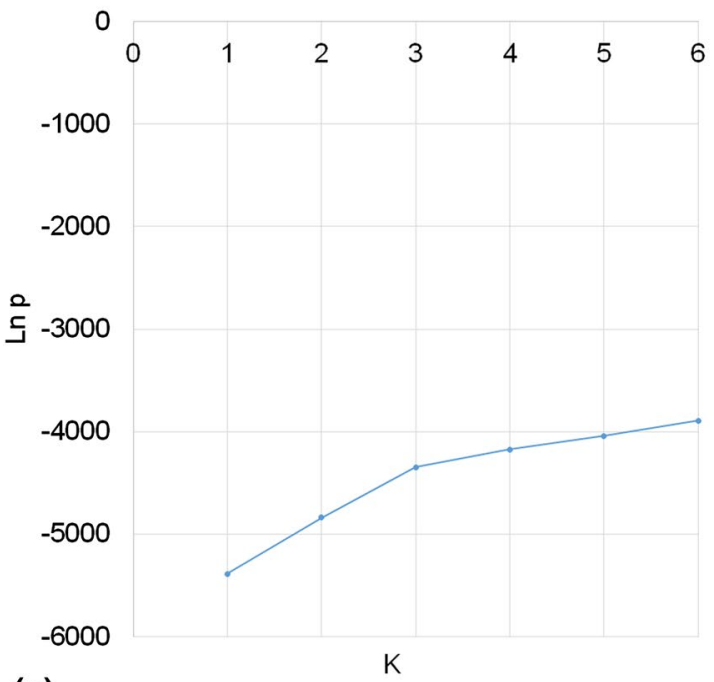

(c)

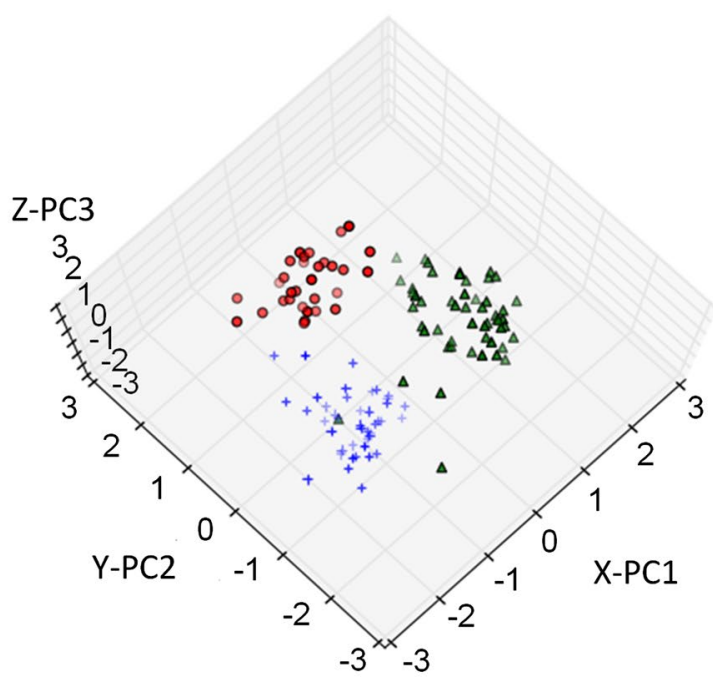

Fig. 5 Population structure analysis of 125 Ae. sharonensis accessions. a Ln $p$ and Delta $K$ plot over subpopulation number $K$. b Delta $K$ plot over subpopulation number $K$. c Projections of the PCA clouds in the space defined by the first three principal components. Three different shapes indicate the subpopulation: red circle subpopulation 1 ; blue cross subpopulation 2; green triangle subpopulation 3. d Geo-

molecular work on this species (Olivera et al. 2007, 2010, 2013; Bouyioukos et al. 2013; Scott et al. 2014) includes the recent construction of a genetic linkage map based on Diversity Technology Array (DArT) markers and simple sequence repeats (SSR) (Olivera et al. 2013). However, some of the linkage groups were incomplete and also characterized by large gaps between markers. In this study, we designed 1536 OPA markers based on the collinearity between Ae. sharonensis and barley using cDNA and genomic shot-gun sequences from key Ae. sharonensis accessions. (b)

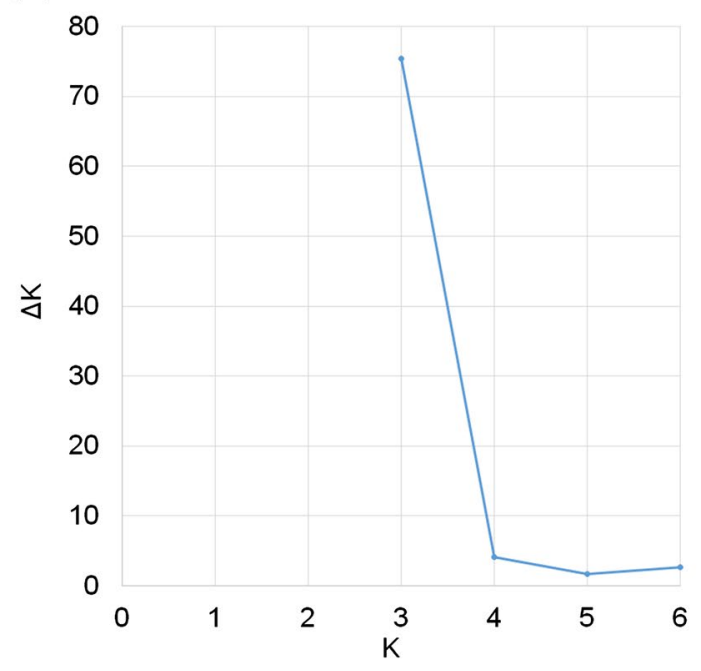

(d)

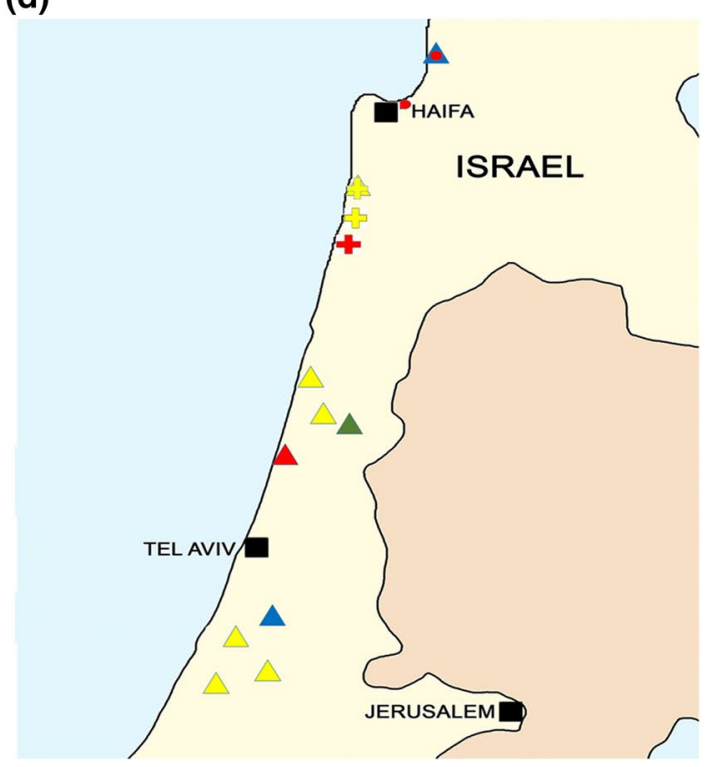

graphical distribution of three subpopulations with various levels of resistance to TTKSK. The shape indicates the subpopulation: circle subpopulation 1; cross subpopulation 2 ; triangle subpopulation 3 . The color indicates the infection type (IT): green 0 , blue $1-11+$, yellow 2-22+, red 3-33+. (Color figure online)

OPA has been applied in many molecular genetic studies of wheat and barley due to its high quality and throughput (Akhunov et al. 2009; Close et al. 2009; Muñoz-Amatriaín et al. 2011). In this study, we developed a consensus OPA genetic linkage map based on two different types of biparental populations, namely one RIL and one $F_{2}$ population. This consensus map consists of 727 OPA markers. Although there are three gaps larger than $10 \mathrm{cM}$, the average distance between two neighbouring markers was $0.9 \mathrm{cM}$. There is a high level of collinearity between the barley and Ae. sharonensis 

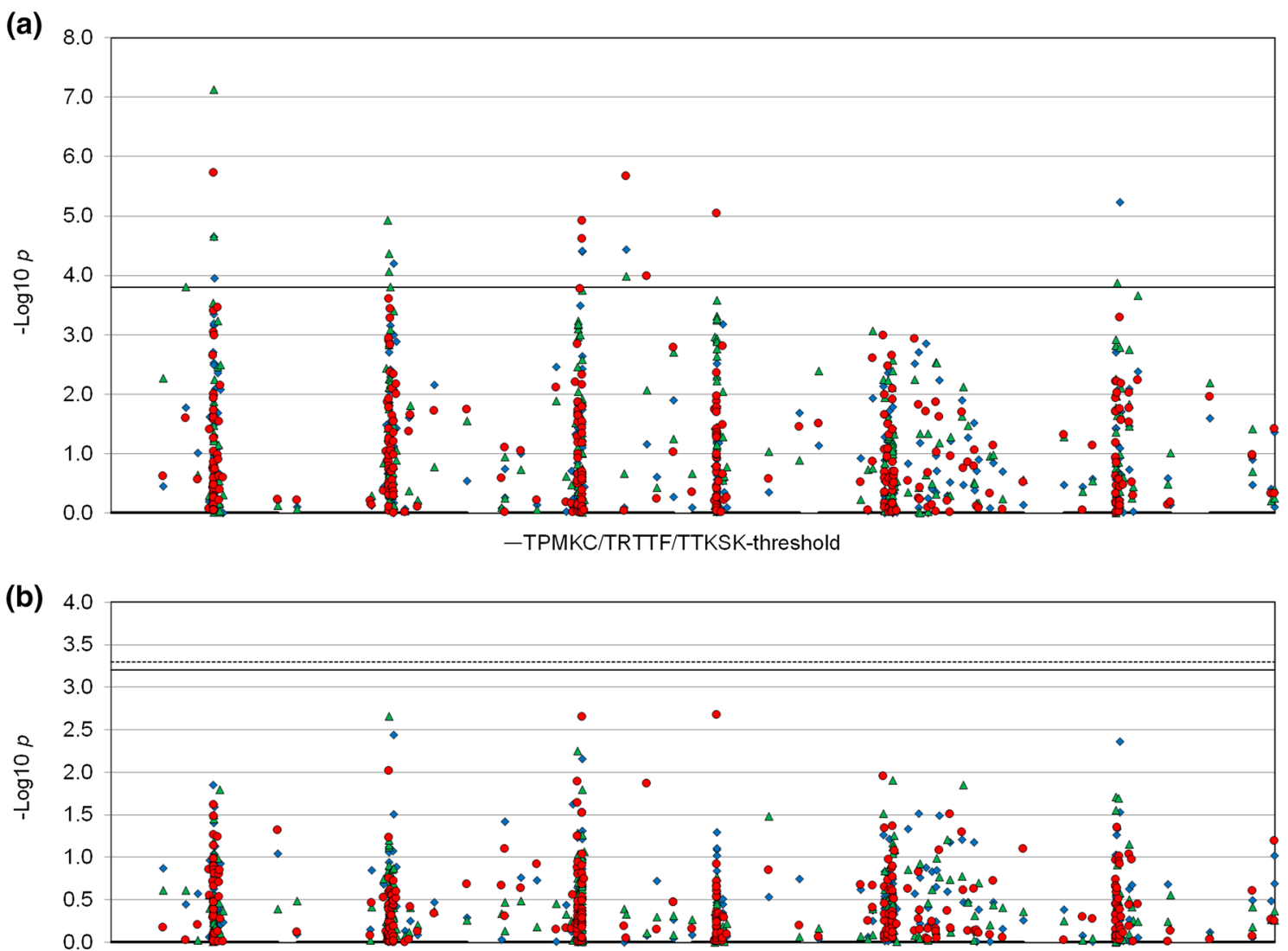

-..-TPMKC-threshold -TRTTF/TTKSK-threshold

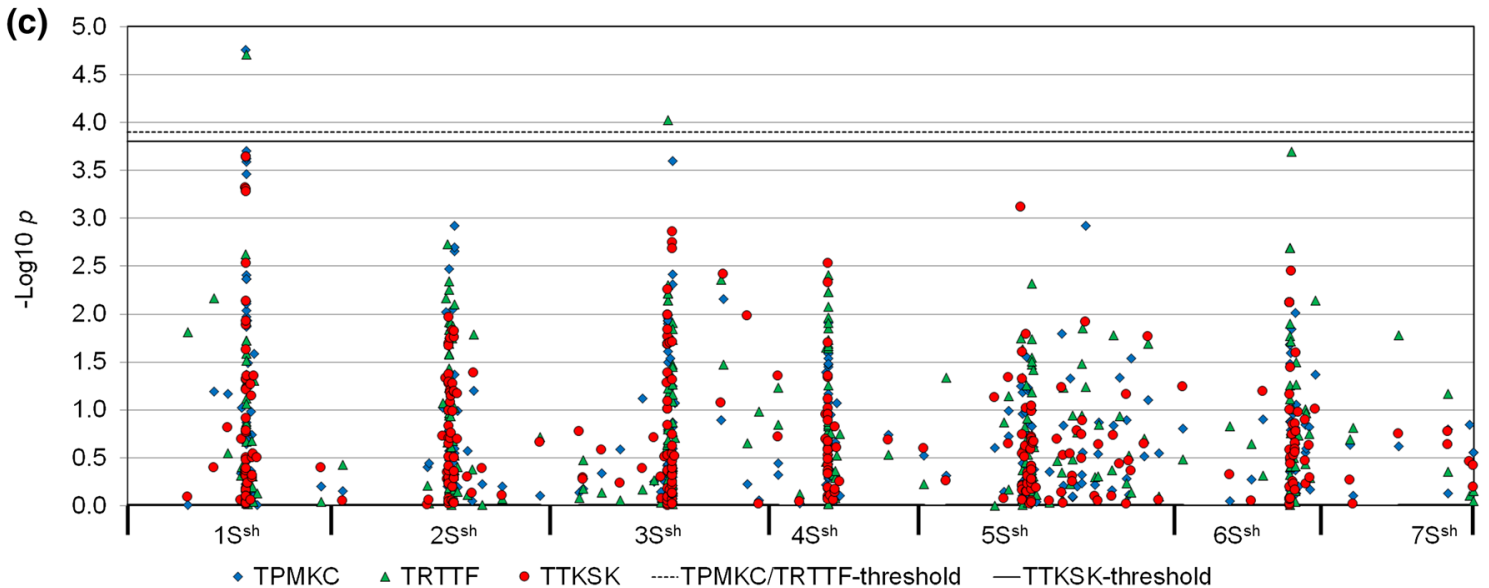

Fig. 6 Genome-wide association study of stem rust resistance in Ae. sharonensis. GLM and MLM analyses were performed on 421 markers and the three Pgt races TPMKC, TRTTF, and TTKSK were used.

chromosomes. Based on BLAST of the mapped Ae. sharonensis OPA marker sequences against barley genome sequences, the seven Ae. sharonensis chromosomes appear to be well covered with markers, except the short arms of chromosomes $3 \mathrm{~S}^{\mathrm{Sh}}$ and $7 \mathrm{~S}^{\mathrm{Sh}}$.
Vertical axes represents $-\log 10 p$ values of the $p$ value of the association. a GLM on 125 accessions; b MLM on 125 accessions; $\mathbf{c}$ GLM$\mathrm{TP}$ on 102 accessions

\section{Biparental population mapping}

We identified two QTL for stem rust resistance to various $P g t$ races including TPMKC, TRTTF, and TTKSK. The two QTL behaved differently in the two populations against these specific races. For example, in the 
$2189 \times 1644$ RIL population, Sr-QTL-1Sh conferred an extremely high level of resistance to TPMKC but only weak resistance to TRTTF, indicating that the $S r$ gene at this locus confers race-specific resistance. Similarly, in this population, $S r-Q T L-5 S h$ conferred a high level of resistance to TRTTF, a relatively low level of resistance to TTKSK, and no significantly detectable resistance to TPMKC (Table 1). Since Sr-QTL-1Sh conferred a high level of resistance, we designated it as gene $\mathrm{Sr}$-1644-1Sh, which indicates the gene is from Ae. sharonensis accession 1644 and located on chromosome $1 S^{\text {Sh }}$. Likewise, we designated the QTL on chromosome $5 \mathrm{~S}^{\mathrm{Sh}}$ as gene Sr-1644-5Sh.

So far, no stem rust resistance gene from tetraploid or hexaploid wheat has been mapped to the short arm of chromosome group 1. However, in the wild diploid species Ae. tauschii, the D genome progenitor of wheat, two genes Sr33 and Sr45 are located on the 1D short arm (Periyannan et al. 2013, 2014). Both Sr33 and Sr45 were recently cloned (Periyannan et al. 2013; Steuernagel et al. 2016). Whether the gene $S r-1644-1 S h$ is an ortholog or homoeolog to any of these genes on the short arm of group 1 is presently unknown. In rye, $\operatorname{Sr} 31\left(\operatorname{Sr} 1 R S^{\text {Amigo }}\right)$, which has been introgressed into wheat, is located on the short arm of chromosome 1R (Wanyera et al. 2006), while another gene from rye, $\mathrm{Sr} 50$, maps close to the centromere on the short arm of rye chromosome 1 (Mago et al. 2015).

In wheat, the gene Sr30 maps to 5DL (Hiebert et al. 2010), but it is not effective against TTKSK. Another gene, Sr49, maps to 5BL (Bansal et al. 2015). Sr53 was recently introgressed from Aegilops geniculata to chromosome arm 5DL of wheat (Liu et al. 2011). In barley, the stem rust resistance locus rpg4/Rpg5 is located on the long arm of 5H (Wang et al. 2013). On the Ae. sharonensis linkage map, the gene $\mathrm{Sr}-1644-5 S h$ is close to $S r 30$. The molecular relationship, if any, between the genes $\mathrm{Sr}$-1644-5Sh, Sr30, Sr49, Sr53 and rpg4/Rpg5 will require further studies.

\section{Genome-wide association study}

Some studies considered the extent of LD as the genetic or physical distance taken for a decay of $r^{2}$ to be an arbitrary value, mostly 0.10 (Remington et al. 2001; Nordborg et al. 2002; Palaisa et al. 2003). We chose the 95th percentile of the distribution of unlinked- $r^{2}$ estimates, including those inter-chromosomal $r^{2}$, as a threshold, which is 0.09 (Fig. 4). The threshold line did not intercept the LOESS regression of the $r^{2}$ across the whole genome, so we were not able to determine the extent of decay. This suggests that the LD of this diversity collection has decayed beyond a statistically detectable level for the marker density in the present map. With decayed LD, the association accuracy of genotype with phenotype (here, disease resistance) should increase while the detecting capability of an association might decrease.

The Ae. sharonensis accessions used in this study were collected within Israel. Structure analysis using the program Structure 3 combined with the ad hoc statistic $\Delta K$ method proposed by Evanno et al. (2005) identified three sub-populations, indicating some degree of diversity in the collection. A similar level of genetic diversity was also reported in another study (Olivera et al. 2009). The PCA defined three subpopulations based on the first three principal components (Fig. 5). We recognize, nonetheless, that the PCA placed four accessions of subpopulation 2 into subpopulation 1 (Fig. 5). This can be explained by differences in the two methods that were applied. The program Structure 2.3.3 along with the method proposed by Evanno et al. (2005) is a Bayesian-based approach (Pritchard et al. 2000), which distributes all the accessions into subpopulations. The PCA method, on the other hand, is essentially based on a few orthogonal principal components, such as the first and second ones, and some accessions might contribute little variation in these components.

The GLM-TP analysis identified two loci significantly associated with stem rust resistance, one on chromosome $1 S^{S h}$ and the other on $3 S^{S h}$. The markers found on chromosome $1 S^{\text {Sh }}$ genetically map to the same positions as the ones which are closest to the QTL peak for resistance to TPMKC or TRTTF in the $2189 \times 1644$ RIL population (Fig. 3; Table 1). We identified the gene $S r-1644-5 S h$ in the $2189 \times 1644$ RIL population, but did not detect any significant marker association by GWAS (with either GLM or GLM-TP). This might be due to lack of closely linked markers in the region around $S r-1644-5 S h$ (Fig. 3) or to a low frequency of $S r-1644-5 S h$ in the diversity panel. The locus on chromosome $3 \mathrm{~S}^{\text {Sh }}$ was not detected in either of the biparental populations. Our results suggest that GWAS can be used as a survey to identify chromosomal regions conferring resistance in a population. However, a major gene with a low allele frequency in the population or minor genes in the population where multiple major genes are present might fall below the detection limit. In contrast, in a biparental population, both major and minor genes (QTL) should be identifiable with adequate population size and genetic linkage map. Therefore, the development of more biparental populations may allow more $S r$ genes to be identified in Ae. sharonensis.

Some researchers argue that marker effects for both population structure $Q$ and kinship $K$ could be over-correcting and might therefore require relaxed $p$ value levels such as 0.001 (Pasam et al. 2012; Zegeye et al. 2014) or require ways to correct for background variations (Yu et al. 2006). In this study, the GLM detected seven loci for resistance to stem rust. Excluding the locus on chromosome $1 \mathrm{~S}^{\mathrm{Sh}}$, all other loci were not detected by QTL mapping in the 
biparental populations. These QTL might reflect true $\mathrm{Sr}$ genes in other resistant accessions or they might be false discoveries. In contrast, the MLM found no marker significantly associated with stem rust resistance even at the relaxed $p$ value of 0.001 (Fig. 6b). Based on the biparental population mapping, we identified two major QTLs/genes (Table 1). The Sr-1644-1Sh region is well covered by markers in the diversity panel and some associated markers had very low $p$ values in the GLM analysis. $S r-1644-1 S h$ should have been detected, but MLM analysis did not detect this gene (Fig. 6b). This indicates that the structure and kinship effects are probably over-corrected using the MLM in this diversity panel. We also tried to minimize the structure and kinship effects by removing closely related accessions based on cluster analysis. Using GLM-TP, one locus on $1 S^{\text {Sh }}$, to where we mapped $S r-1644-1 S h$ in the biparental populations, was detected against both TPMKC and TRTTF, and another locus on $3 \mathrm{~S}^{\text {Sh }}$ was also detected, suggesting that GLM-TP might be the better way for GWAS in terms of reducing false discovery rate and over-correcting.

GWAS is a useful tool which can be used as a survey to identify potential loci of interest in the genome of a species using a germplasm diversity collection from a discrete geographical area to nation- or world-wide. However, the success of GWAS to define traits of interest relies on multiple factors, including population structure, linkage map density, marker quality, minor allele frequency, and the number of genes contributing to the trait. Some genes for a trait may not be identified due to gaps in the linkage map. Markers such as some SSRs, amplify at multiple loci, thus reducing the effectiveness of the detection of association between a marker and a trait. The vast majority of single nucleotide polymorphism (SNP) markers amplify at only one locus. The SNP-based OPA is a high throughput and high quality marker system that can be used to improve genome coverage and linkage density. The consensus OPA genetic linkage map developed in this study should be beneficial for regular gene/QTL mapping in a biparental population. For GWAS, we would advocate the generation of a denser genetic map, such as can be achieved with genotyping-by-sequencing ( $\mathrm{Li}$ et al. 2015) or the Illumina 9k or 90k SNP platform (Wang et al. 2014).

In this study, we developed the first whole genome genetic linkage map for Ae. sharonensis using OPA markers. By QTL mapping, we identified two novel wheat stem rust resistance genes, Sr-1644-1Sh and Sr-1644-5Sh, in Ae. sharonensis. While gene $\mathrm{Sr}$-1644-1Sh confers strong resistance to races TTKSK and TPMKC, the gene $S r-1644-5 S h$ confers a high level of resistance to race TRTTF. The genetic isolation of $S r-1644-1 S h$ and $S r-1644-5 S h$ in an otherwise susceptible background and the generation of a genetic linkage map now allows these genes to be targeted for molecular isolation (cloning) through map-based approximation or mutational genomics (MutRenSeq; Steuernagel et al. 2016). Furthermore, the development of linked markers would facilitate their introgression from Ae. sharonensis into hexaploid wheat (Millet et al. 2014). Sr-1644-1Sh was also detected by GWAS, but $S r-1644-5 S h$ was not detected. This study highlights the importance of QTL mapping in a biparental population to support GWAS as previously demonstrated for downy mildew resistance in Arabidopsis (Nemri et al. 2010).

Author contribution statement GY, NC, BS, PDO, JS, CW, RJ, MJM, IH-P, PG and EM performed experiments. GY and BBHW wrote the manuscript. GY, MJM, HS, JDGJ, ERW, BJS and BBHW contributed to the design of the study.

Acknowledgements We thank the University of California, Los Angeles, Neuroscience Genomics Core for the OPA genotyping of $A$ e. sharonensis. This research was supported by the BBSRC, 2Blades Foundation, Gatsby Foundation, Bill \& Melinda Gates Foundation and the UK Department for International Development to Cornell University for the Borlaug Global Rust Initiative Durable Rust Resistance in Wheat Project, and the Lieberman-Okinow Endowment at the University of Minnesota.

\section{Compliance with ethical standards}

Conflict of interest The authors declare that they have no conflict of interest.

Open Access This article is distributed under the terms of the Creative Commons Attribution 4.0 International License (http:// creativecommons.org/licenses/by/4.0/), which permits unrestricted use, distribution, and reproduction in any medium, provided you give appropriate credit to the original author(s) and the source, provide a link to the Creative Commons license, and indicate if changes were made.

\section{References}

Akhunov E, Nicolet C, Dvorak J (2009) Single nucleotide polymorphism genotyping in polyploid wheat with the Illumina GoldenGate assay. Theor Appl Genet 119:507-517

Anugrahwati DR, Shepherd KW, Verlin DC, Zhang P, Mirzaghaderi G, Walker E, Francki MG, Dundas IS (2008) Isolation of wheatrye 1 RS recombinants that break the linkage between the stem rust resistance gene $S r R$ and secalin. Genome 51:341-349

Bansal UK, Muhammad S, Forrest KL, Hayden MJ, Bariana HS (2015) Mapping of a new stem rust resistance gene Sr49 in chromosome 5B of wheat. Theor Appl Genet 128:2113-2119

Bariana HS, McIntosh RA (1993) Cytogenetic studies in wheat XIV. Location of rust resistance genes in VPM1 and their genetic linkage with other disease resistance genes in chromosome $2 \mathrm{~A}$. Genome 36:476-482

Belkhir K, Borsa P, Chikhi L, Raufaste N, Bonhomme F (1996-2004) GENETIX 4.05, logiciel sous Windows pour la génétique des populations. Université de Montpellier II, Montpellier, France 
Bouyioukos C, Moscou MJ, Champouret N, Hernández-Pinzón I, Ward ER, Wulff BBH (2013) Characterisation and analysis of the Aegilops sharonensis transcriptome, a wild relative of wheat in the Sitopsis section. Plos One 8:e72782

Brenchley R, Spannagl M, Pfeifer M, Barker GLA, D'Amore R, Allen AM, McKenzie N, Kramer M, Kerhornou A, Bolser D, Kay S, Waite D, Trick M, Bancroft I, Gu Y, Huo N, Luo M-C, Sehgal S, Gill B, Kianian S, Anderson O, Kersey P, Dvorak J, McCombie WR, Hall A, Mayer KFC, Edwards KJ, Bevan MW, Hall N (2012) Analysis of the bread wheat genome using whole-genome shotgun sequencing. Nature 491:705-710

Churchill GA, Doerge RW (1994) Empirical threshold values for quantitative trait mapping. Genetics 138:963-971

Cleveland WS (1979) Robust locally weighted regression and smoothing scatterplots. J Am Stat Assoc 74:829-836

Close TJ, Bhat PR, Lonardi S, Wu Y, Rostoks N, Ramsay L, Druka A, Stein N, Svensson JT, Wanamaker S, Bozdag S, Roose ML, Moscou MJ, Chao S, Varshney RK, Szucs P, Sato K, Hayes PM, Matthews DE, Kleinhofs A, Muehlbauer GJ, DeYoung J, Marshall DF, Madishetty K, Fenton RD, Condamine P, Graner A, Waugh R (2009) Development and implementation of highthroughput SNP genotyping in barley. BMC Genomics 10:582

Dundas IS, Anugrahwati DR, Verlin DC, Park RF, Bariana HS, Mago R, Islam AKMR (2007) New sources of rust resistance from alien species: ameliorating linked defects and discovery. Aust J Agric Res 58:545-549

Evanno G, Regnaut S, Goudet J (2005) Detecting the number of clusters of individuals using the software STRUCTURE: a simulation study. Mol Ecol 14:2611-2620

Falush D, Stephens M, Pritchard JK (2003) Inference of population structure using multilocus genotype data: linked loci and correlated allele frequencies. Genetics 164:1567-1587

Hardy OJ, Vekemans X (2002) SPAGeDi: a versatile computer program to analyse spatial genetic structure at the individual or population levels. Mol Ecol Notes 2:618-620

Hiebert CW, Fetch TG, Zegeye T (2010) Genetics and mapping of stem rust resistance to Ug99 in the wheat cultivar Webster. Theor Appl Genet 121:65-69

International Barley Genome Sequencing Consortium, Mayer KF, Waugh R, Brown JW, Schulman A, Langridge P, Platzer M, Fincher GB, Muehlbauer GJ, Sato K, Close TJ, Wise RP, Stein N (2012) A physical, genetic and functional sequence assembly of the barley genome. Nature 491:711-716

International Wheat Genome Sequencing Consortium (2014) A chromosome-based draft sequence of the hexaploid bread wheat (Triticum aestivum) genome. Science 345:1251788

Jin Y, Szabo LJ, Pretorius ZA, Singh RP, Ward R, Fetch T Jr (2008) Detection of virulence to resistance gene $\mathrm{Sr} 24$ within race TTKS of Puccinia graminis f. sp. tritici. Plant Dis 92:923-926

Jin Y, Szabo LJ, Rouse MN, Fetch T Jr, Pretorius ZA, Wanyera R, Njau P (2009) Detection of virulence to resistance gene Sr36 within the TTKS race lineage of Puccinia graminis f. sp. tritici. Plant Dis 93:367-370

Kim D, Pertea G, Trapnell C, Pimentel H, Kelley R, Salzberg SL (2013) TopHat2: accurate alignment of transcriptomes in the presence of insertions, deletions and gene fusions. Genome Biol 14:R36. doi:10.1186/gb-2013-14-4-r36

Klindworth DL, Niu Z, Chao S, Friesen TL, Jin Y, Faris JD, Cai X, $\mathrm{Xu}$ SS (2012) Introgression and characterization of a goatgrass gene for a high level of resistance to $\mathrm{Ug} 99$ stem rust in tetraploid wheat. G3 Genes Genom Genet 2:665-673

Knight E, Binnie A, Draeger T, Moscou M, Rey MD, Sucher J, Mehra S, King I, Moore G (2015) Mapping the 'breaker' element of the gametocidal locus proximal to a block of sub-telomeric heterochromatin on the long arm of chromosome $4 \mathrm{~S}^{\text {sh }}$ of Aegilops sharonensis. Theor Appl Genet 128:1049-1059
Kosambi D (1944) The estimation of map distance from recombination values. Ann Euge 12:172-175

Li H, Durbin R (2009) Fast and accurate short read alignment with Burrows-Wheeler transform. Bioinformatics 25:1754-1760

Li H, Handsaker B, Wysoker A, Fennell T, Ruan J, Homer N, Marth G, Abecasis G, Durbin R (2010) Genome project data processing subgroup (2009) The sequence alignment/map format and SAMtools. Bioinformatics 25:2078-2079

Li H, Vikram p, Singh RP, Kilian A, Carling J, Song J, Burgueno-Ferreira JA, Bhavani S, Huerta-Espino J, Payne T, Sehgal D, Wenzl P, Singh S (2015) A high density GBS map of bread wheat and its application for dissecting complex disease resistance traits. BMC Genomics 16:216

Liu W, Jin Y, Rouse M, Friebe B, Gill B, Pumphrey MO (2011a) Development and characterization of wheat-Ae. searsii Robertsonian translocations and a recombinant chromosome conferring resistance to stem rust. Theor Appl Genet 122:1537-1545

Liu W, Rouse M, Friebe B, Jin Y, Gill B, Pumphrey MO (2011b) Discovery and molecular mapping of a new gene conferring resistance to stem rust, Sr53, derived from Aegilops geniculata and characterization of spontaneous translocation stocks with reduced alien chromatin. Chromosome Res 19:669-682

Liu W, Rouse M, Friebe B, Jin Y, Gill B, Pumphrey MO (2011c) Discovery and molecular mapping of a new gene conferring resistance to stem rust, Sr53, derived from Aegilops geniculata and characterization of spontaneous translocation stocks with reduced alien chromatin. Chromosome Res 19:669-682

Liu W, Danilova TV, Rouse MN, Bowden RL, Friebe B, Gill BS, Pumphrey MO (2013) Development and characterization of a compensating wheat-Thinopyrum intermedium Robertsonian translocation with $\mathrm{Sr} 44$ resistance to stem rust (Ug99). Theor Appl Genet 126:1167-1177

Mago R, Verlin D, Zhang P, Bansal U, Bariana H, Jin Y, Ellis J, Hoxha S, Dundas I (2013) Development of wheat-Aegilops speltoides recombinants and simple PCR-based markers for Sr32 and a new stem rust resistance gene on the $2 \mathrm{~S} \# 1$ chromosome. Theor Appl Genet 126:2943-2955

Mago R, Zhang P, Vautrin S, Šimková H, Bansal U, Luo MC, Rouse M, Karaoglu H, Periyannan S, Kolmer J, Jin Y, Ayliffe MA, Bariana H, Park RF, McIntosh R, Doležel J, Bergès H, Spielmeyer W, Lagudah ES, Ellis JG, Dodds PN (2015) The wheat Sr50 gene reveals rich diversity at a cereal disease resistance locus. Nat Plants 1:15186

Manly KF, Cudmore RH Jr, Meer JM (2001) Map manager QTX, cross-platform software for genetic mapping. Mamm Genome 12:930-932

Mayer KF, Rogers J, Doležel J, Pozniak C, Eversole K, Feuillet C, Gill B, Friebe B, Lukaszewski AJ, Sourdille P, Endo TR, Kubaláková M, Cíhalíková J, Dubská Z, Vrána J, Sperková R, Simková H, Febrer M, Clissold L, McLay K, Singh K, Chhuneja P, Singh NK, Khurana J, Akhunov E, Choulet F, Alberti A, Barbe V, Wincker P, Kanamori H, Kobayashi F, Itoh T, Matsumoto T, Sakai H, Tanaka T, Wu J, Ogihara Y, Handa H, Maclachlan PR, Sharpe A, Klassen D, Edwards D, Batley J, Olsen OA, Sandve SR, Lien S, Steuernagel B, Wulff B, Caccamo M, Ayling S, Ramirez-Gonzalez RH, Clavijo BJ, Wright J, Pfeifer M, Spannagl M, Martis MM, Mascher M, Chapman J, Poland JA, Scholz U, Barry K, Waugh R, Rokhsar DS, Muehlbauer GJ, Stein N, Gundlach H, Zytnicki M, Jamilloux V, Quesneville H, Wicker T, Faccioli P, Colaiacovo M, Stanca AM, Budak H, Cattivelli L, Glover N, Pingault L, Paux E, Sharma S, Appels R, Bellgard M, Chapman B, Nussbaumer T, Bader KC, Rimbert H, Wang S, Knox R, Kilian A, Alaux M, Alfama F, Couderc L, Guilhot N, Viseux C, Loaec M, Keller B, Praud S (2014) A chromosomebased draft sequence of the hexaploid bread wheat (Triticum aestivum) genome. Science 345. doi:10.1126/science. 1251788 
McIntosh RA, Yamazaki Y, Dubcovsky J, Rogers J, Morris C, Appels R, Xia XC (2013) Catalogue of gene symbols for wheat. http:// www.shigen.nig.ac.jp/wheat/komugi/genes/download.jsp. Accessed 18 June 2016. Committee for the National. BioResource Project (NBRP)/KOMUGI, Japan

McVey DV, Long DL, Roberts JJ (2002) Races of Puccinia graminis in the United States during 1997 and 1998. Plant Dis 86:568-572

Millet E, Manisterski J, Ben-Yehuda P, Distelfeld A, Deek J, Wan A, Chen X, Steffenson BJ (2014) Introgression of leaf rust and stripe rust resistance from Sharon goatgrass (Aegilops sharonensis Eig) into bread wheat (Triticum aestivum L.). Genome 57:309-316

Muñoz-Amatriaín M, Moscou MJ, Bhat PR, Svensson JT, Bartoš J, Suchánková $\mathrm{P}$, Šimková $\mathrm{H}$, Endo TR, Fenton RD, Lonardi S, Castillo AM, Chao S, Cistué L, Cuesta-Marcos A, Forrest KL, Hayden MJ, Hayes PM, Horsley RD, Makoto K, Moody D, Sato K, Vallés MP, Wulff BBH, Muehlbauer GJ, Doležel J, Close TJ (2011) An improved consensus linkage map of barley based on flow-sorted chromosomes and single nucleotide polymorphism markers. Plant Genome 4:238-249

Nemri A, Atwell S, Tarone AM, Huang Y, Zhao K, Studholme DJ, Nordborg M, Jones JDG (2010) Genome-wide survey of Arabidopsis natural variation in downy mildew resistance using combined association and linkage mapping. PNAS 107:10302-10307

Newcomb M, Olivera PD, Rouse MN, Szabo LJ, Johnson J, Gale S, Luster DG, Wanyera R, Macharia G, Bhavani S, Hodson D, Patpour M, Hovmoller MS, Fetch TG Jr, Jin Y (2016) Characterization of Kenyan isolates of Puccinia graminis f. sp. tritici from 2008 to 2014 reveals virulence to SrTmp in the Ug99 race group. Phytopathology 100:986-996

Niu Z, Klindworth DL, Friesen TL, Chao S, Jin Y, Cai X, Xu SS (2011) Targeted introgression of a wheat stem rust resistance gene by DNA marker-assisted chromosome engineering. Genetics 187:1011-1021

Niu Z, Klindworth DL, Yu G, Friesen TL, Chao S, Jin Y, Cai X, Ohm JB, Rasmussen JB, Xu SS (2014) Development and characterization of wheat lines carrying stem rust resistance gene Sr43 derived from Thinopyrum ponticum. Theor Appl Genet 127:969-980

Nordborg M, Borevitz JO, Bergelson J, Berry CC, Chory J, Hagenblad J, Kreitman M, Maloof JN, Noyes T, Oefner PJ, Stahl EA, Weigel D (2002) The extent of linkage disequilibrium in Arabidopsis thaliana. Nat Genet 30:190-193

Olivera PD, Kolmer JA, Anikster Y, Steffenson BJ (2007) Resistance of Sharon goatgrass (Aegilops sharonensis) to fungal diseases of wheat. Plant Dis 91:942-950

Olivera PD, Anikster Y, Steffenson BJ (2010) Genetic diversity and population structure in Aegilops sharonensis. Crop Sci 50:636-648

Olivera PD, Jin Y, Rouse M, Badebo A, Fetch T Jr, Singh RP, Yahyaoui A (2012) Races of Puccinia graminis f. sp. tritici with combined virulence to $\operatorname{Sr} 13$ and $S r 9 e$ in a field stem rust screening nursery in Ethiopia. Plant Dis 96:623-628

Olivera PD, Kilian A, Wenzl P, Steffenson BJ (2013) Development of a genetic linkage map for Sharon goatgrass (Aegilops sharonensis) and mapping of a leaf rust resistance gene. Genome $56: 367-376$

Olivera P, Newcomb M, Szabo LJ, Rouse M, Johnson J, Gale S, Luster DG, Hodson D, Cox JA, Burgin L, Hort M, Gilligan CA, Patpour M, Justesen AF, Hovmøller MS, Woldeab G, Hailu E, Hundie B, Tadesse K, Pumphrey M, Singh RP, Jin Y (2015) Phenotypic and genotypic characterization of race TKTTF of Puccinia graminis f. sp. tritici that caused a wheat stem rust epidemic in southern Ethiopia in 2013-14. Phytopathology 105:917-928

Palaisa KA, Morgante M, Williams M, Rafalski A (2003) Contrasting effects of selection on sequence diversity and linkage disequilibrium at two phytoene synthase loci. Plant Cell 15:1795-1806

Pasam R, Sharma R, Malosetti M, van Eeuwijk F, Haseneyer G, Kilian B et al (2012) Genome-wide association studies for agronomical traits in a world wide spring barley collection. BMC Plant Biol 12(1):16. doi:10.1186/1471-2229-12-16

Periyannan S, Moore J, Ayliffe M, Bansal U, Wang X, Huang L, Deal K, Luo M, Kong X, Bariana H, Mago R, McIntosh R, Dodds P, Dvorak J, Lagudah E (2013) The gene Sr33, an ortholog of barley Mla genes, encodes resistance to wheat stem rust race Ug99. Science 341:786-788

Periyannan S, Bansal U, Bariana H, Deal K, Luo MC, Dvorak J, Lagudah E (2014) Identification of a robust molecular marker for the detection of the stem rust resistance gene $\mathrm{Sr} 45$ in common wheat. Theor Appl Genet 127:947-955

Pretorius ZA, Singh RP, Wagoire WW, Payne TS (2000) Detection of virulence to wheat stem rust resistance gene $\mathrm{Sr} 31$ in $\mathrm{Puc}$ cinia graminis $\mathrm{f}$. sp. tritici in Uganda. Plant Dis 84:203

Pritchard JK, Stephens M, Donnelly P (2000) Inference of population structure using multilocus genotype data. Genetics 155:945-959

Qi LL, Pumphrey MO, Friebe B, Zhang P, Qian C, Bowden RL, Rouse MN, Jin Y, Gill BS (2011) A novel Robertsonian translocation event leads to transfer of a stem rust resistance gene (Sr52) effective against race Ug99 from Dasypyrum villosum into bread wheat. Theor Appl Genet 123:159-167

Remington DL, Thornsberry JM, Matsuoka Y, Wilson LM, Whitt SR, Doebley J, Kresovich S, Goodman MM, Buckler ES (2001) Structure of linkage disequilibrium and phenotypic associations in the maize genome. Proc Natl Acad Sci USA 98:11479-11484

Roelfs A, McVey D (1979) Low infection types produced by Puccinia graminis $\mathrm{f}$. sp. tritici and wheat lines with designated genes for resistance. Phytopathology 69:722-730

Scott JC, Manisterski J, Sela H, Ben-Yehuda P, Steffenson BJ (2014) Resistance of Aegilops species from Israel to widely virulent African and Israeli races of the wheat stem rust pathogen. Plant Dis 91:942-950

Singh RP, Hodson DP, Jin Y, Huerta-Espino J, Kinyua MG, Wanyera R, Njau P, Ward R (2006) Current status, likely migration and strategies to mitigate the threat to wheat production from race Ug99 (TTKS) of stem rust pathogen. CAB Rev Perspect Agric Vet Sci Nutr Nat Resour 1(54):1-13

Singh RP, Hodson DP, Huerta-Espino J, Jin Y, Bhavani S, Njau P, Herrera-Foessel S, Singh PK, Singh S, Govindan V (2011) The emergence of $\mathrm{Ug} 99$ races of the stem rust fungus is a threat to world wheat production. Annu Rev Phytopathol 49:465-481

Singh RP, Hodson DP, Jin Y, Lagudah ES, Ayliffe MA, Bhavani S, Rouse MN, Pretorius ZA, Szabo LJ, Huerta-Espino J, Basnet BR, Lan C, Hovmøller MS (2015) Emergence and spread of new races of wheat stem rust fungus: Continued threat to food security and prospects of genetic control. Phytopathology 105:872-884

Stakman EC, Stewart DM, Loegering WQ (1962) Identification of physiological races of Puccinia graminis var. tritici. United States Department of Agriculture, Agricultural Research Service E-617, NewYork

Steuernagel B, Periyannan SK, Hernández-Pinzón I, Witek K, Rouse MN, Yu G, Hatta A, Ayliffe M, Bariana H, Jones JDG, Lagudah ES, Wulff BBH (2016) Rapid cloning of disease-resistance genes in plants using mutagenesis and sequence capture. Nat Biotechnol 34:652-655

Tsilo TJ, Chao S, Jin Y, Anderson JA (2009) Identification and validation of SSR markers linked to the stem rust resistance gene Sr6 on the short arm of chromosome 2D in wheat. Theor Appl Genet 118:515-524 
Wang S, Basten CJ, Zeng ZB (2006) Windows QTL Cartographer 2.5. Department of Statistics. North Carolina State University, Raleigh. http://statgen.ncsu.edu/qtlcart/WQTLCart.htm

Wang X, Richards J, Gross T, Druka A, Kleinhofs A, Steffenson B, Acevedo M, Brueggeman R (2013) The rpg4-mediated resistance to wheat stem rust (Puccinia graminis) in barley (Hordeum vulgare) requires Rpg5, a second NBS-LRR gene, and an actin depolymerization factor. Mol Plant Microbe Interact 26:407-418

Wang S, Wong D, Forrest K, Allen A, Chao S, Huang BE, Maccaferri M, Salvi S, Milner SG, Cattivelli L, Mastrangelo AM, Whan A, Stephen S, Barker G, Wieseke R, Plieske J, International Wheat Genome Sequencing Consortium, Lillemo M, Mather D, Appels R, Dolferus R, Brown-Guedira G, Korol A, Akhunova AR, Feuillet C, Salse J, Morgante M, Pozniak C, Luo MC, Dvorak J, Morell M, Dubcovsky J, Ganal M, Tuberosa R, Lawley C, Mikoulitch I, Cavanagh C, Edwards KJ, Hayden M, Akhunov E (2014) Characterization of polyploid wheat genomic diversity using a high-density 90,000 single nucleotide polymorphism array. Plant Biotechnol J 12:787-796

Wanyera R, Kinyua MG, Jin Y, Singh RP (2006) The spread of stem rust caused by Puccinia graminis f. sp. tritici, with virulence on Sr31 in wheat in Eastern Africa. Plant Dis 90:113
Williams ND, Miller JD, Klindworth DL (1992) Induced mutations of a genetic suppressor of resistance to wheat stem rust. Crop Sci 32:612-616

Yu J, Pressoir G, Briggs WH, Vroh Bi I, Yamasaki M, Doebley JF, McMullen MD, Gaut BS, Nielsen DM, Holland JB (2006) A unified mixed-model method for association mapping that accounts for multiple levels of relatedness. Nat Genet 38:203-208

Yu GT, Zhang Q, Klindworth DL, Friesen TL, Knox R, Jin Y, Zhong S, Cai X, Xu SS (2010) Molecular and cytogenetic characterization of wheat introgression lines carrying the stem rust resistance gene Sr39. Crop Sci 50:1393-1400

Yu LX, Barbier H, Rouse MN, Singh S, Singh RP, Bhavani S, HuertaEspino J, Sorrells ME (2014) A consensus map for Ug99 stem rust resistance loci in wheat. Theor Appl Genet 127:1561-1581

Zegeye H, Rasheed A, Makdis F, Badebo A, Ogbonnaya FC (2014) Genome-wide association mapping for seedling and adult plant resistance to stripe rust in synthetic hexaploid wheat. PLoS One 9(8):e105593. doi:10.1371/journal.pone.0105593 